\title{
A Method for Solving Two-Variable Simultaneous Nonlinear Equations
}

\author{
Ikuho Yamada, Won-Hi Hong*, Hideki Mori, Chizu Nakao \\ and Fang-Zhi Liu
}

\begin{abstract}
Department of Applied Chemistry, Nagoya Institute of
Technology, Nagaya 466

Key Words : Numerical Solution, Iterative Method, Bubble Point Calculation at Chemical Equilibrium, Calculation for Quenching

A numerical method has been proposed for solving strongly nonlinear simultaneous equations with two variables by improving the Wegstein method for one variable. The features of the proposed method are i) to use only an initial value, ii) to provide stability of the solution with simplicity of algorithm, and iii) to reduce the C.P.U. time required. The superiority of this method is demonstrated by two sample calculations, bubble point at chemical equilibrium and a quenching.
\end{abstract}

* Korea Advanced Institute of Science and Technology

\section{$\mathrm{Si}$ 単結晶面におけるベンゼンおよびピリジンの吸着 ${ }^{\dagger}$ \\ 一偏光解析法による吸着層厚みの測定 — 神吉達夫・浅野 強・財津国央・陳 永展 ${ }^{*}$ \\ 姫路工業大学工学部 産業機械工学科 ${ }^{\dagger \dagger}$}

\section{緒 言}

結晶構造の明確な固体表面を対象としての吸着平衡関 係や分子配向など吸着特性を明らかにすることは，触媒 能, 表面反応, 分子識別能など機能発現の要因である吸 着質と表面の相互作用を明らかにする上で重要である. しかし, 活性面が微小な表面での吸着特性を実験的に評 価するとなると, 容積法や重量法など従来の方法では対 応できない，近年，FTIRやRaman分光法などの光学的 手法が界面の特性評侕の手段として適用されているが, 吸着量や表面濃度などの定量に対しては必ずしも有力な 方法とは云えない，吸着量を定量するには，吸着層の厚 みに直接目を向ける方がより適切であると考えられる。

本研究では，吸着質の表面濃度の測定手段の確立を目 的として, 偏光解析法に着目し, シリコン単結晶面にお

\footnotetext{
† 1992年11月 5 日受理 ; 化学工学会第 24 回秋季大会 (名古屋, 1991年10月), 同浜松大会 (静岡, 1992年11月) にて発表

†† $\mathbf{T} 671-22$ 姫路市書写 2167

* 花王 (株) 情報科学研究所
}

けるベンゼンおよびピリジンの吸着層厚みの測定を試み た。吸着層厚みが被覆率と比例関係にあるとして吸着平 衡特性を考察し，その結果に基づいて飽和単分子層の厚 み，吸着質占有面積および吸着熱を推定した。また，分 子種による吸着層厚みの差異について, 紫外発光や Ramanスペクトルに基づく既往の結果 ${ }^{1,9)}$ との対応関係 についても考察した.

\section{1. 偏光解析の原理}

偏光した光が界面に入射すると, 界面の光学的特性を 反映して偏光状態の異なる光が反射される. この特性を 利用すると, 界面における吸着物質の膜厚みや屈折率な ど光学定数を測定することが可能となる ${ }^{3,10)}$. 今, 入射面 に平行な入射光の電場の振動成分を $\bar{E}_{p i}$, 垂直な振動成 分を $\bar{E}_{s i}$ とすると, それぞれの反射光の振動成分 $\bar{E}_{p r}, \bar{E}_{s}$, は次式で関係づけられる。

$$
\bar{E}_{p r}=\bar{R}_{p} \bar{E}_{p i}, \bar{E}_{s r}=\bar{R}_{s} \bar{E}_{s i}
$$

分子は表面で局在しておりステップ状の層を形成してい る屯のと考えられる。しかし，入射光束が分子占有面積 


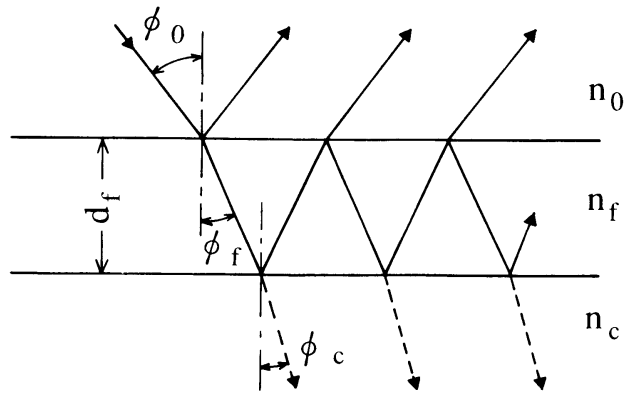

Fig. 1 Scheme of multi-reflection of light in an adsorbed layer

に比して充分大きい面積を有するとき，反射光は平均化 された表面の情報を反映するすのと考えられる，そこで， 吸着層は均一な厚みを有するあのと仮定する．Fig. 1 に 示すように，吸着層での多重反射による干渉を考慮する 之, 反射率 $\bar{R}_{j}(j=p, s)$ は次式で与えられる.

$$
R_{j}=\frac{r_{1 j}+r_{2 j} \exp (-i \delta)}{1+r_{1 j} r_{2 j} \exp (-i \delta)}=r_{j} \exp \left(i \delta_{j}\right), j=p, s
$$

$\delta$ は光が吸着層内の $\mathrm{V}$ 字光路を一往復する際に生じる位 相の遅れで, 吸着層の厚み $d_{f}$, 気相, 吸着層, 吸着媒の 屈折率 $n_{0}, n_{f}, \bar{n}_{c}\left(=n_{c}-i k\right)$ と次式で関係づけられる.

$$
\delta=4 \pi\left(d_{f} / \lambda\right)\left(n_{f}^{2}-n_{0}^{2} \sin ^{2} \phi_{0}\right)^{1 / 2}
$$

$r_{1 j}, r_{2 j}(j=p, s)$ はそれぞれ気相一吸着層（第1）界面打 よび吸着層一吸着媒（第 2) 界面に抢ける Fresnelの複素 振幅反射率である.

$$
\begin{aligned}
& r_{1 p}=\frac{\tan \left(\phi_{0}-\phi_{f}\right)}{\tan \left(\phi_{0}+\phi_{f}\right)} \quad r_{1 s}=-\frac{\sin \left(\phi_{0}-\phi_{f}\right)}{\sin \left(\phi_{0}+\phi_{f}\right)} \\
& r_{2 p}=\frac{\tan \left(\phi_{f}-\phi_{c}\right)}{\tan \left(\phi_{f}+\phi_{c}\right)} \quad r_{2 s}=-\frac{\sin \left(\phi_{f}-\phi_{c}\right)}{\sin \left(\phi_{f}+\phi_{c}\right)}
\end{aligned}
$$

ここに， $\phi_{0}$ は気相から吸着層への入射角， $\phi_{f}, \phi_{c}$ はそれ ぞれ吸着層拉よび吸着媒での光の屈折角で, それぞれ Snell の法則により関係づけられる.

光の偏光状態は, 光の直交二成分の振幅比之相対的な 位相差, すなわち複素振幅比 $\bar{\chi}=\bar{E}_{s} / \bar{E}_{p}$ で表現される. 反射光之入射光の複素振幅比は, Eqs. (1a, b) より, $\bar{\chi}_{r}=$ $\bar{E}_{s} r / \bar{E}_{p r}=\left(\bar{R}_{s} / \bar{R}_{p}\right) \bar{\chi}_{i}=\rho^{-1} \bar{\chi}_{i} . \rho$ は複素反射率比之呼 ばれ次式で与えられる.

$$
\begin{gathered}
\rho=\left|\bar{R}_{p} / \bar{R}_{s}\right| \exp \left[i\left(\delta_{p}-\delta_{s}\right)\right]=\tan \psi \exp [i \Delta], \\
0 \leqq \psi \leqq \pi / 4, \quad 0 \leqq \Delta<2 \pi
\end{gathered}
$$

振幅反射率の絶対值の比, $\left|\bar{R}_{p} / \bar{R}_{s}\right|(=\tan \psi)$ 执よび $p$ 成分之 $s$ 成分の位相差 $\Delta$ は Eq. (2) と Fresnel の式より吸 着層の吸着層厚み $d_{f}$ 拉よび屈折率 $n_{f}$ 亿関係づけられる. $n_{f}$ があらかじめ既知な場合, 等屈折率曲線から層厚み $d_{f}$ を決定することができる.

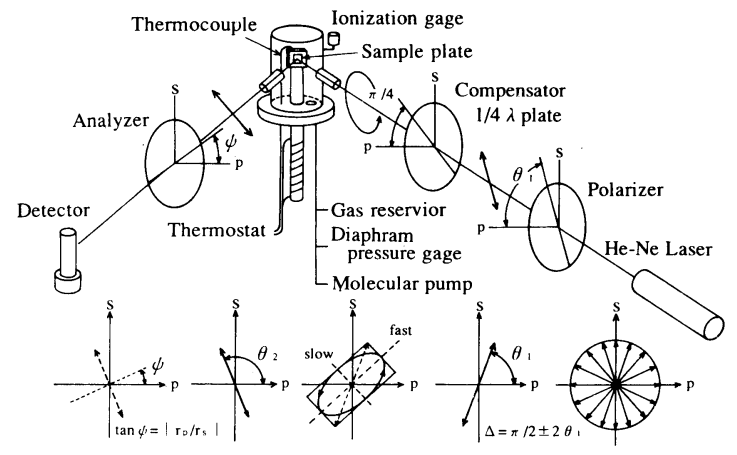

Fig. 2 Experimental apparatus and optical path of polarized beam

\section{2. 実験装置および方法}

実験装置の概略をFig. 2 亿示す．真空容器はステンレ ス製（直径 $100 \mathrm{~mm}$ ，高さ $190 \mathrm{~mm}$ ）で入射・反射光透過 用の光学グラスが取り付けられている. 内部には, 吸着 媒素片 $\left(10 \times 10 \mathrm{~mm}^{2}\right)$ が支柱先端の固定台 $(20 \mathrm{~mm}$ 立方 $)$ に取り付けられている。吸着媒の温度は銅製熱伝導棒を 通して制御される。入射角は支柱を中心としたアームに より調整される。本実験では $65^{\circ}$ に設定した。光路系お よび各光学素子を透過した光の偏光状態は図に示したと おりである。レーザー光 $(\mathrm{He}-\mathrm{Ne}, \lambda=632.8 \mathrm{~nm}, 5 \mathrm{~mW}$ ， ランダム偏光, ビーム径約 $1 \mathrm{~mm}$ ) は偏光子 (M. GRIOT, 03FPG003) で直線偏光とされる. $p$ 軸に対して $45^{\circ}$ に設 定された $1 / 4$ 波長板（M. GRIOT, 02WRQ001)に入射し た光は電場の fast 軸成分が速められ slow 軸成分が遅延 され両者に $\pi / 2$ の移相差を生じ棈円偏光とされる. この 光は吸着媒表面に照射され, 反射光は検光子（偏光子） を経て光電管で光強度が検出される. 光強度の信号は $\mathrm{A}$ /D コンバータを通してマイクロコンピュータに記録処理 される. この際, 反射光が再び直線偏光となるように, 偏光板 $\left(\theta_{1}\right)$ と検光子 $\left(\theta_{2}\right)$ を回転させる $\left(\theta_{1}\right.$ と $\theta_{2}$ を交互 に変化させ光強度が最低となる角度を探す (消光法) ). 偏光子の回転角より $\Delta$, 検光子の回転角より $\Psi$ が決定さ れる. 表面に吸着気体がない状態 (ターボ分子ポンプ(大 阪真空 TMP 50)で $10^{-4} \mathrm{~Pa}$ 域とし $50^{\circ} \mathrm{C}$ で15時間以上脱気 した）での基準值 $\Psi_{0} ， \Delta_{0}$ を測定する。試料気体を所定の 圧力で導入し, 平衡状態を確認し $\Psi, \Delta$ 值を測定する. なお，各光学素子はステッピングモー夕により精度 $0.015^{0}$ で回転制御される。吸着媒には, シリコン単結晶 (001) を，吸着質として，ベンゼンとピリジン（吸着分子配向 についての分光学的知見が報告されている ${ }^{1,9)}$ を採用し た. 実験温度域は, $20 \sim 40^{\circ} \mathrm{C}$ で, 実験圧力域は $p / p_{s}=$ 0〜0.7である. 


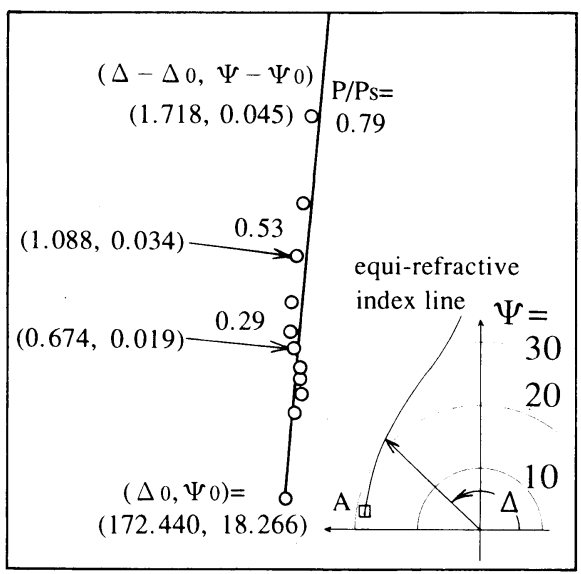

Fig. 3 Illustration of equi-refractive index curve, pyridine on $\mathrm{Si}$ surface at $25^{\circ} \mathrm{C}, n_{0}=1, n_{c}=$ $3.92, k_{c}=0.361, n_{f}=1.51$

\section{3. 実験結果および考察}

Fig. 3 はピリジンに対して測定された $\Delta, \Psi$ 值を極座標 で表示した一例（座標系の図で $\mathrm{A}$ 部を拡大した）を示し ている. 点 $\left(\Delta_{0}, \Psi_{0}\right)$ は吸着質のない表面の $\Delta, \Psi$ 值を示 している，図の実線は，吸着質が液体状であると仮定し た等屈折率曲線 $\left(n_{f}=1.498 ; D(N a)\right.$ および $\mathrm{H}_{\alpha}(\mathrm{C})$ 線で の值 ${ }^{6)}$ より補間した）である。実測值はこの曲線上にの っている.乙のことは，Eq.(3)の関係およびFig. 1から わかるように, 吸着層の厚み $d$ が光路差 $\delta$ に比例するこ とを示している，乙の図より，各相対圧に対して， $\Delta_{0}, \Psi-\Psi_{0}$ の值が知れる. たとえば $20^{\circ} \mathrm{C}$ では, $\Delta_{0}=$ $172.49( \pm 0.06), \Psi_{0}=18.27( \pm 0.015)$ で, $\Delta$ は $\Delta-\Delta_{0}=0$ 〜 $1.8^{0}, \Psi$ は $\left|\Psi-\Psi_{0}\right|<0.05^{0}$ の範囲で変化した．本実 験域では, $\Psi$ 変化は小さく, 等屈折率曲線はほぼ $\Psi=$ $\Psi_{0}$ 上にあり, 吸着層厚み $d_{f}$ は $\Delta$ の変化として検出され た. $\Delta$ 値の変化は吸着質種によって顕著に異なるが，温 度依存性は認められなかった。

Fig. 4 は，20，30，40ㄷ におけるベンゼンおよびピリジ ンの各測定圧力における吸着相厚みを示している。吸着 層厚みは，いずれの吸着質についても，同圧においては 温度が低くなるほど大きい値を示す。一般に，第 1 層で は吸着分子は表面との相互作用により配向し，第 2 層以 上では液体状であるとされている。吸着層厚み $d_{f}$ から吸 着分子数 $n_{a}$ を推定するためには，吸着層の構造が明確で なければならないが，乙こでは，数分子層内においては， 各層の層厚みが均一で, 被覆率 $\theta$ が $d_{f}$ に比例するもの之 仮定する．乙のとき，1 分子層の厚みを $d_{m}$ とすると， $\theta$ $=d_{f} / d_{m}$ とおくことができ, $n_{a}=n_{s} \theta=n_{s} d_{f} / d_{m}$ と表現さ れる。乙れより，図の縦軸は吸着量に比例すると考えら れ, ベンゼンはBDDT 分類でIII型, ピリジンは II 型の吸

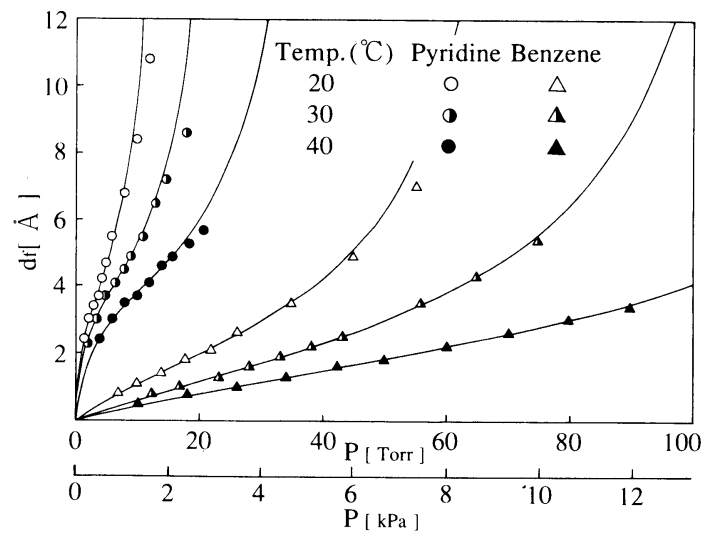

Fig. 4 Thickness of adsorbed layer vs pressure, benzene and pyridine on Si surface, with BET correlation

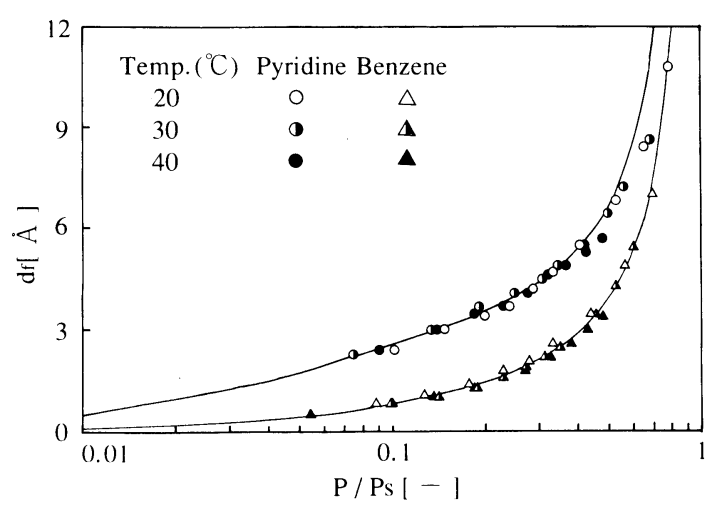

Fig. 5 Thickness of adsorbed layer against specific pressure

着等温挙動を示すすのと判断される.

Fig. 5 は，吸着層厚み $d_{f}$ を相対压の対数に対して整理 した結果を示している。これによると，本実験温度域で 涼，吸着層の厚みは各吸着質についてそれぞれほぼひと

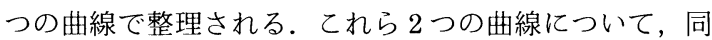
相対圧ではピリジンの吸着層厚みはベンゼンに比してか なり大きい值をとることが認められる。

吸着等温式として， $n_{f}$ に対し液体の值を用いたことか ら $\mathrm{BET}$ 式 $^{2)}$ を適用すると, 被覆率志るいは吸着層厚みは 次式で与えられる.

$$
\begin{gathered}
\theta=d_{f} / d_{m}=B \bar{p} /[(1-\bar{p})(1-\bar{p}+B \bar{p})], \\
\vec{p}=p / p_{0}
\end{gathered}
$$

$d_{m}$ と吸着平衡定数比 $B$ は, $\bar{p} /(1-\bar{p}) d_{f}$ と $\bar{p}$ の值線関係 より求められるが，乙こでは，BET式の適用範囲である $p / p_{0}=0.05 \sim 0.35$ の圧力域で測定值を相関するよう最小 二乗法を用いて決定した。その結果をTable 1 亿示す. 分子占有面積 $S_{m}$ の值は吸着質が液体状で高さ $d_{m}$ の層内 で最密充媜されているとして，モル体積の值 $\left(20^{\circ} \mathrm{C}\right.$ での 
Table 1 Monomolecular layer thickness and occupied area of adsorbate

\begin{tabular}{|c|c|c|c|c|c|c|c|}
\hline Adsorbate & $\begin{array}{c}d_{m} \\
{[\AA]}\end{array}$ & & $\begin{array}{c}S_{m} \\
{\left[\AA^{2}\right]}\end{array}$ & & $\begin{array}{c}B \\
{[-]}\end{array}$ & $\begin{array}{c}q_{a} \\
{[\mathrm{~kJ} / \mathrm{mol}]}\end{array}$ & $\begin{array}{c}q_{e} \\
{[\mathrm{~kJ} / \mathrm{mol}]}\end{array}$ \\
\hline Benzene & 2.52 & 58.6 & $52.7^{*}$ & $30.7^{\#}$ & 3.5 & 32.4 & $31.7^{+}$ \\
\hline Pyridine & 3.52 & 38.0 & $38.2^{* *}$ & $28.7^{\#}$ & 16.8 & 40.3 & $39.6^{++}\left(35.1^{+++}\right)$ \\
\hline \multicolumn{8}{|c|}{$\begin{array}{l}\left.* \text { on } \mathrm{SiO}_{2} \text { at } 20^{\circ} \mathrm{C}^{8}, * * \text { on Graphite at } 20^{\circ} \mathrm{C}^{8}\right) \text {, \# estimated from hexagonal } \\
\text { closest packing model, }+ \text { at } 25.05^{\circ} \mathrm{C}(94 \mathrm{mmHg}),++ \text { at } 24.8 \sim 46.8^{\circ} \mathrm{C} \text {, from } \\
\text { Clausius-Clapeyron equation, }+++ \text { at } 115.25^{\circ} \mathrm{C}(760 \mathrm{mmHg})\end{array}$} \\
\hline
\end{tabular}

値 ${ }^{4)}$ を用いた）から $S_{m}=v_{m} / N_{A} d_{m}$ より算定した。ピリジ ンとベンゼンは分子量, 分子構造とあ類似しているにあ かかわらず，ピリジンの $d_{m}$ はベンゼンのそれに比して約 1.4 倍の値を示している，また，占有面積はベンゼンの 方がピリジンの約 1.5 倍の直を示して抢り, 既往の結果 ${ }^{8)}$ ともよく対応している. 比較のため, 分子が球状である として, $S_{m}=1.091\left(v_{m} / N_{A}\right)^{2 / 3}$ より求めた值を表仁記し ている。 てれらの值は実測值より幾分小さい值を与えて いる。これらのことから，ピリジンは環を立てた状態で, ベンゼンは環を伏せた状態で吸着するものと推測される. このととは, 界面分光学から得られている吸着質と表面 の相互作用，すなわち，ピリジンが表面と $\sigma$ 結合し，心゙ ンゼンが $\pi$ 結合するとする報告にも適合する ${ }^{1,7,9)}$. Figs. $\mathbf{5 , 6}$ の実線は $d_{m}$ とBに対して Table 1 の值を用いて計算 された吸着等温線である. 実線は実測値をよく相関して いる.

吸着熱は等量吸着熱で, $q_{a}=k T^{2}(\partial \ln p / \partial T)_{d f}$ より求 めた（表の值は $d_{f}=d_{m} / 2$ での值である）。吸着熱は蒸発 熱に比してわずかに高い値を示している。一般に，II型 吸着では, $q_{a}>q_{e}$, III 型では $q_{a}<q_{e}$ とされているが, ここではその差異は認められなかった。

な扔, 本測定法の問題点として, 原理的には $n_{f}$ と $d_{f}$ の同時椡定が可能であるが， $\Psi$ の変化が小さく特定の $n_{f}$ 值に対する等屈折率曲線の識別が困難で, 吸着層の屈折 率を仮定しなければならない点が上げられる．特に， $\theta$ $\ll 1$ では分子配向や結晶表面の露出などにより $n_{f}$ が $\theta$ の 関数であるあの之推察される. また，解析上での問題之 して, 各層の厚みが均一であるとしたてとが上げられる. これらの問題については, 吸着層の構造と光の特性の観 点からより厳密な考察が必要であると思われる.

\section{結 言}

シリコン単結晶面におけるべンゼンおよびピリジンの 吸着について, 偏光解析法による吸着層厚みの測定を試 みた。その結果，1）吸着層厚みは吸着質の種類によう て異なるが，同相対圧では温度にほとんど依存しない， 2）吸着層厚みと相対圧の関係は, 吸着層厚みが被覆率 と比例すると仮定することにより BET 式で相関される,
3) ピリジンの単分子層厚みはベンゼンのそれより大きい 値をとる，4）ベンゼンの吸着分子占有面積はピリジン よりあ大きい值をとる，乙となどを示した．

吸着層厚みと被覆率との関係についてより厳密な考察 が加えられるべきであるが，平坦な結晶表面での吸着平 衡特性を評価する手段として偏光解析法は有効な測定手 段であると結論される.

\section{Nomenclature}

$d_{i}=$ thickness of adsorbed layer, $i=f, m$ $[\mathrm{m}]$

$\bar{E}_{j q}=$ amplitude of $j$-component of electric field vector, $j=p, s, q=i, r$ $[\mathrm{volt} / \mathrm{m}]$

$n$ = refractive index

$N_{A}=$ Avogadro number

$k$ = damping coefficient

$p=$ pressure

$\vec{p} \quad=$ specific pressure $=p / p_{s}$

$q$ = adsorption or evaporation energy

$r_{j}=$ Fresnel's reflectivity

$\bar{R}_{j}=$ reflectivity of adsorbed layer

$S_{m}=$ occupied area of adsorbed molecule $\left[\mathrm{m}^{2}\right]$

$v_{m}=$ molar volume of liquid state adsorbate $\left[\mathrm{m}^{3}\right]$

$\delta=$ phase delay due to path difference

[rad]

$\Delta=$ phase difference between $E_{p}$ and $E_{s}$

[rad]

$\phi=$ angle of incidence or of refraction

[rad]

$\Psi=$ arctangent of refractivities ratio

$$
=\tan ^{-1}\left(\left|\bar{R}_{p}\right| /\left|\bar{R}_{s}\right|\right)
$$

$<$ Subscripts $>$

0 = gas phase, incident side

$a$ adsorbed

$e$ = evaporation

$c=$ solid phase, penetrated side

$f=$ film, adsorbed layer

$i=$ incident

$m$ = monomolecular layer or molecular

$r=$ reflective 


$$
\begin{aligned}
& p=\text { parallel } \\
& s=\text { senkrecht (normal) or saturated }
\end{aligned}
$$

\section{Literature cited}

1) Bandy, B.J. and D.R. LLoyd and N.V. Richardson: Surface Sci., 89, pp. 344-353 (1979)

2) Brunauer, S., P.H. Emmett and E. Teller: J. Amer. Chem. Soc., 60, 309-319 (1938)

3) Balkanski, M., J.I. Carasso and H.U. Harten: "Surface Science, Recent Developments in Ellipsometry”, pp.217-233, pp.265-287, North-Holland (1969)

4) Inoue, K., I. Ohishi, et al.: "Kagaku Benran”, Ed. by H. Kanbe, p. 566, Maruzen (1975)

5) Kinoshita, K. and H. Yokota: Ohyo Butsuri, 34, pp. 782-794 (1965)

6) Kinoshita, H., S. Kubo, et al.: "Kagaku Benran", Ed. by K. Kutsu, p.1258, Maruzen (1975)

7) Kishi, K. and S. Ikeda: J. Phys. Chem. 73, pp.25592564 (1969)

8) McClellan, A.L. and H.F. Harnsberger: J. Colloid and Interface Sci., 23, pp.577-599 (1967)

9) Simpson, S.F. and J.M. Harris: J. Phys. Chem., 94, pp. 4649-4654 (1990)

10) Yamamoto, M.: “Jikken Butsurigaku Koza 14", pp. 123-168, Kyoritsu (1986)

\title{
Adsorption of Benzene and Pyridine on Si Crystal Surface - Measurements of Adsorbed Layer Thickness by Ellipsometry -
}

\author{
Tatsuo Kanki, Tsuyoshi Asano, Kunio Zaitsu \\ and Yung Chan Chen* \\ Department of Chemical Engineering, Faculty of Engineering, \\ Himeji Institute of Technology, Himeji 671-22
}

Key Words : Adsorption, Ellipsometry, Adsorbed Layer Thickness, Isotherm, Benzene, Pyridine, Silicon

Ellipsometry is used for measuring adsorption layer thicknesses of benzene and pyridine on silicon crystal surface (001). Variations of the thickness with specific pressures are shown to be correlated well by the BET multilayer adsorption isotherm equation, which allows us to estimate the thicknesses of saturated monomolecular layer and molecular occupied areas. It was found that the monomolecular layer thickness of pyridine is about 40 percent greater than that of benzene, while the occupied area of a pyridine molecule is about 60 percent less than that of a benzene molecule. These conclusions are coincident with spectroscopic results reported for adsorbate-surface interaction by means of UV photoemission and Raman spectroscopy. Ellipsometry has been proved to be an effective method for evaluating adsorption equilibrium characteristics.

* Recording \& Imaging Science Laboratories, Kao Co. Ltd., 2606 Akabane, Haga 321-34 